\title{
BODY COMPOSITION AND HAND GRIP STRENGTH IN HEALTHY COMMUNITY-DWELLING OLDER ADULTS IN SWEDEN
}

\author{
A. Lindblad', S. Dahlin-Ivanoff', I. Bosaeus², E. Rothenberg ${ }^{3}$
}

\begin{abstract}
Background: Longevity increases worldwide but there are few studies on body composition and hand grip strength in populations over 80 years. Given high prevalence of chronic disease and functional disability in octogenarians, it may be difficult to distinguish effects of ageing from those imposed by disease. The European Consensus definition of sarcopenia recommends using both low muscle mass and function for diagnosis. Objectives: Examine body composition and hand grip strength in a selected group of community-dwelling older adults with high level of functional independence. In addition, longitudinal changes in handgrip strength were examined using previously collected data. Design: Cross-sectional body composition and hand grip strength with a four year retrospective analysis on previously assessed hand grip strength. Setting: Measurements were conducted by home visits. Participants: 102 community-dwelling 83-96 year-olds, 50 \% women. Measurements: Hand grip strength was registered by a dynamometer and body composition analysis using bioimpedance spectroscopy. Results: According to European Consensus definition, only 6/102 had normal muscle mass - no men, although $78 \%$ of men and $40 \%$ of women had normal muscle strength. Since previously collected data four years earlier, men had lost strength $(p<0.001)$, while women had not ( $p=0.202)$. Conclusions: Subject characteristics and health status support well-preserved body energy, protein stores and muscle strength. Low muscle mass was much more prevalent than low muscle strength. Results may give an indication of what constitutes a healthy body composition in oldest old and could serve as a starting point for reference values on healthy body composition in octogenarians.
\end{abstract}

Key words: Body composition, hand grip strength, older adults, octogenarian.

\section{Introduction}

Longevity increases worldwide but there are few studies on body composition and hand grip strength in populations over 80 years. Given the high prevalence of chronic disease and functional disability in the oldest age groups, in population-based studies it may be difficult to distinguish effects due to ageing from those imposed by disease.

Body composition shifts during aging: from middle age muscle mass decrease and fat mass increase (1-3). Reduced muscle mass diminish muscle strength and muscle function which can increase the risk of sarcopenia, falls and fractures (1-5).

The European Consensus definition of sarcopenia recommends using the presence of both low muscle mass and low muscle function (strength and performance) for diagnosis (3). It further defines three conceptual stages

1. Gothenburg University, Department of Clinical Neuroscience and Rehabilitation, Sweden; 2. Gothenburg University, Department of Internal Medicine and Clinical Nutrition, Sweden; 3. Kristianstad University, Food and Meal Science, Sweden

Corresponding Author: Amanda Lindblad, Gothenburg University, Department of Clinical Neuroscience and Rehabilitation, Sweden, amanda.julia.lindblad@gmail. com of sarcopenia: Presarcopenia, with low muscle mass only; Sarcopenia, with low muscle mass and low muscle strength or performance; and severe sarcopenia, with low muscle mass, strength and performance

Bioelectrical impedance spectroscopy (BIS) is an easy, non-invasive method to assess body composition, including muscle mass $(6,7)$. Skeletal muscle mass indicates protein reserves and physical function $(3,7,8)$. As a measure of physical function, hand grip strength is cheap and simple, often used to evaluate muscle strength $(3,9)$.

The present study is a follow-up extension of a previous study, Elderly Persons in the Risk Zone, in which community-dwelling subjects aged 80 years and over with a high level of functional independence were examined (10).

The aims of the present study were to examine body composition, and hand grip strength in a selected group of community-dwelling men and women, 80 years and older with a high level of functional independence. In addition, changes in handgrip strength over time were examined using previously collected data. 


\section{Methods}

The study population was recruited from the Elderly Persons in the Risk Zone-study in Gothenburg, Sweden's 2nd largest city, in a city district with high socioeconomic status compared to the rest of the city. Baseline assessments, including hand grip strength were collected in 2008 on 459 men and women of 80 years and older - 343 remaining at 2-year follow-up in 2010. Inclusion criteria were living in ordinary homes, independence of municipal home care service or help in ADL, and no cognitive impairment. Complete description of the Elderly Persons in the Risk Zone-study can be found elsewhere (10).

In 2012, 284 individuals were still alive and well. Inclusion criteria in present study were communitydwelling and still living within the city district. Enrollment period was March 2012. A random subsample of the 284 individuals was contacted by two registered dietitians. Gender distribution was equalized by continuous enrollment until 51 men and 51 women were included. A total of 151 individuals were contacted, 49 declined to participate due to illness, nursing home residence or time constraints, see Figure 1. No difference in year of birth, sex, marital status, education, occupation or handgrip strength in neither 2008 nor 2010 between participants and those who declined to participate ( $p>0.05)$. Participants were born in 1916-28.

A previous population study on older adults from Gothenburg was used as comparison to present population: The Gerontological and Geriatric Population Study (H70) in 75 year olds $(6,11,12)$.

Measurements and an interview including subject characteristics were carried out through home visits.

\section{Anthropometry}

Body height $(\mathrm{BH})$ was measured standing against a wall without shoes, using a metallic measure tape to nearest $0.1 \mathrm{~cm}$, body weight (BW) with light indoor clothing, using an EKS Electronic Scale $(0-180 \mathrm{~kg})$ to the nearest $0.1 \mathrm{~kg}, 1 \mathrm{~kg}$ was deducted for clothes. Body mass index (BMI) was calculated as $\mathrm{BW} / \mathrm{BH}^{2}$ and classified as normal weight within $22-30 \mathrm{~kg} / \mathrm{m}^{2}$ according to Swedish recommendations for older adults $(13,14)$.

\section{Strength}

Hand grip strength was measured by a JAMAR hydraulic hand held dynamometer according to the manufacturer's instructions with maximum force of three attempts registered (15). If dominant hand was or recently had been damaged, both hands were measured and highest reading used. Data is missing from two participants in 2012. Hand grip strength from previous study in 2008 was used for longitudinal comparison (10).

\section{Body composition}

BIS-analysis was carried out using Imp SFB7 (Impedimed Brisbane, Australia), operating frequency of $4-1000 \mathrm{kHz}$ (16). Extra cellular water and intracellular water were calculated according to Impedimed equations in Software Bioimp version 1.0.0 (16). Resistance and reactance at $50 \mathrm{kHz}$ was used to calculate phase angle as $\arctan \left(\frac{X c}{R}\right) \times\left(\frac{180}{\Pi}\right)$ and phase angle standard deviation score was calculated as $\frac{(x-M P h A)}{S P}$ using age, gender and BMIspecific cut-offs (17). sarcopenia was assessed by gender and defined as muscle mass $\leq 8.50 \mathrm{~kg} / \mathrm{m}^{2}$ for men and $\leq$ $5.75 \mathrm{~kg} / \mathrm{m}^{2}$ for women $(7,8)$. Skeletal muscle index and percentage skeletal muscle mass was calculated from skeletal muscle mass, retrieved from the equation by Tengvall et al (6):

$-23.053+(0.333 \times B H)+(-0.004 \times R i)+(-0.010 \times R e)+(-1.727 \times G e n d e r)+(0.042 \times B W)$.

Where resistance ( $\mathrm{Ri}, \mathrm{Ohms}$ ) and reactance (Re, Ohms) is retrieved from the BIS, $\mathrm{BH}$ in $\mathrm{cm}$, gender: $\mathrm{men}=0$, women $=1$ and BW in $\mathrm{kg}(6)$.

\section{Ethical approval}

Informed written consent was obtained from all participants. The Regional Ethical Review Board in Gothenburg approved the present study as an addition (T176-12) to the Elderly Persons in the Risk Zone-study (Dnr 650-07).

\section{Statistical analysis}

All analyses were carried out using IBM SPSS Statistics 20 . Descriptive results are presented as mean $\pm S D$. Significance level was set to $p<0.05$. Analyses of body composition and hand grip strength were stratified by age (83-89 vs 90-96 years) and by gender. Sarcopenia was assessed with gender specific cut-offs (3). Data was tested for normally distribution using the Kolmogorov-Smirnov test. Paired t-test was used to examine longitudinal changes, independent t-test and ANOVA with Bonferroni adjustment was used to analyze differences between groups. Linear regression was used for analysis of the relation between skeletal muscle index and hand grip strength.

\section{Results}

We examined 102 participants between 83-96 years old of which $50 \%$ were women. Subject characteristics are shown in Table 1 and anthropometry, body composition and hand grip strength are presented in Table 2.

According to the classification of Cruz-Jentoft et al (3), none of the men had normal muscle, 10/51 (20\%) had moderate sarcopenia, and 41/51 (80\%) had severe sarcopenia. For women, corresponding numbers were 6/51 (12\%), 23/51 (45\%) and 22/51 (43\%), see Table 2. 
When hand grip strength was classified as normal or low by the criteria of Cruz-Jentoft et al, 40/50 (80\%) of men and 20/50 (40\%) of women had normal HGS (data missing from one man and one woman) (3).

Table 1

Subject characteristics

\begin{tabular}{lll}
\hline & Men & Women \\
\hline Age & $86.4( \pm 3.0)$ & $86.5( \pm 2.9)$ \\
Education (n) & & \\
Elementary & 15 & 29 \\
High school & 7 & 3 \\
Higher Degree/University * & 29 & 19 \\
Occupation (n) & & \\
Office & 46 & 35 \\
Labor & 5 & 16 \\
Housing (n) & & \\
Apartment & 38 & 45 \\
House & 13 & 6 \\
Household (n) & & 38 \\
Single * & 19 & 13 \\
With partner & 32 & \\
* Difference between sex (p<0.02) & & \\
\hline
\end{tabular}

Figure 1

\section{Recruitment process}

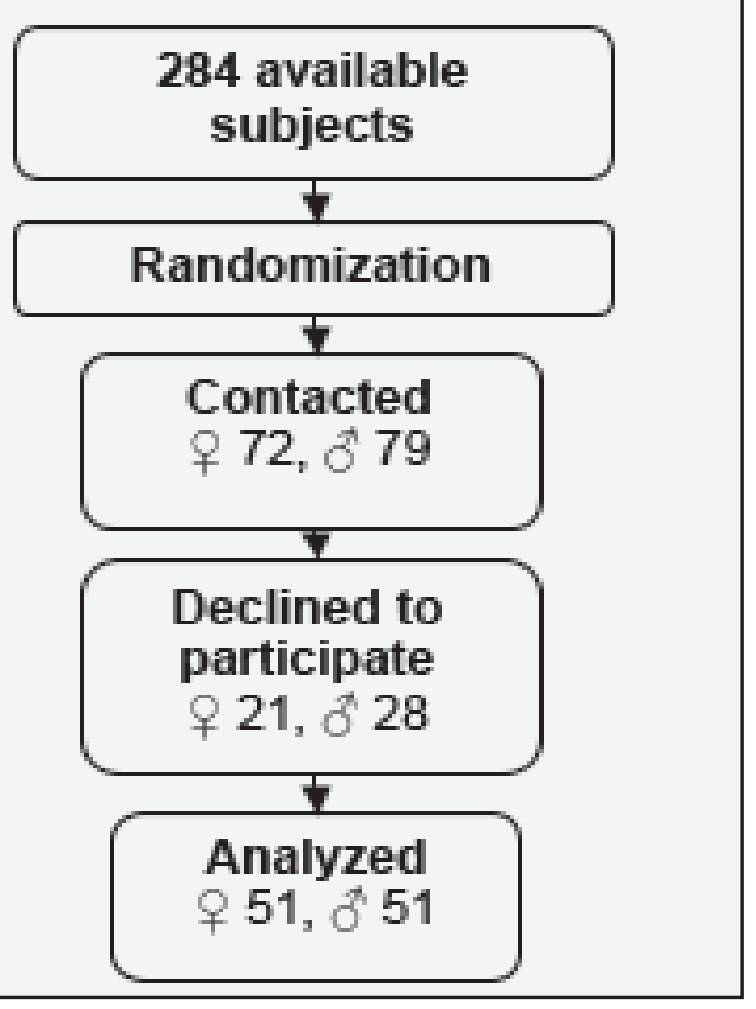

A low fat free mass index was found in $11 / 51$ men $(22 \%)$, and $8 / 51$ women (16\%) according to cut-offs for FFMI by Kyle et al (18). fat mass index was high in $10 / 51$ men $(20 \%)$ and $4 / 51$ women $(8 \%)$, and otherwise normal except for one woman, who had a low fat mass index (18).

The linear relation between muscle mass (expressed as skeletal muscle index. and muscle strength (expressed as hand grip strength) was $\mathrm{r}=.477(\mathrm{p}<0.001)$ in men and $\mathrm{r}=.320(\mathrm{p}=0.023)$ in women. Men classified with moderate sarcopenia had a hand grip strength of $38.5 \mathrm{~kg}$, compared to $33.1 \mathrm{~kg}$ in those with severe sarcopenia $(\mathrm{p}>0.05)$. For women, corresponding numbers were 19.4 and $18.8 \mathrm{~kg}$. Women with normal muscle mass had a mean hand grip strength of $22.3 \mathrm{~kg}(\mathrm{p}>0.05)$.

Handgrip strength for total study population in 2012 ranged from 10 to $29 \mathrm{~kg}$ for women and 20 to $50 \mathrm{~kg}$ for men, mean presented in Table 2. Men were significantly stronger than women $(p=<0.001)$. When hand grip strength per skeletal muscle mass was divided by sex, differences in strength did not remain $(p=0.329)(6)$. Skeletal muscle mass was negatively correlated with age, more so in men than women. No difference was found in phase angle according to sex, age and household status. Men and women classified as severe sarcopenic had lower phase angle $(\mathrm{p}=0.012)$.

In comparison to the population of 75 year olds from the H70-study, our population had lower weight $(\mathrm{p}<0.001), B M I(p<0.001)$, skeletal muscle mass $(\mathrm{p}=0.008)$, skeletal muscle index $(\mathrm{p}<0.001)$ and phase angle $(\mathrm{p}<0.001)$ (6).

\section{Age related differences}

We found no difference in fat free mass $(p=0.512)$ in those over 90 years of age $(n=15)$ compared to those under, although a tendency to lower fat mass was observed $(p=0.046)$.

\section{Longitudinal changes}

Over the four year period of follow-up, men had lost hand grip strength $(\mathrm{p}<0.001)$, while women had not $(\mathrm{p}=0.202)$. For men classified with moderate sarcopenia, the decline was $3.1 \mathrm{~kg}$, and in those with severe 5.4 $\mathrm{kg}(\mathrm{p}>0.05)$. For women, corresponding values were $3.8 \mathrm{~kg}$ and $2.3 \mathrm{~kg}$. Women with normal muscle mass had lost $3 \mathrm{~kg}$ ( $p>0.05)$. Unexpectedly, subjects with low muscle mass classified as severe sarcopenic in 2012 had higher hand grip strength in $2008-30.8 \mathrm{~kg}$ compared to $25.3(\mathrm{p}=0.01)$ and in $2012-28.3 \mathrm{~kg}$ compared to $24.4 \mathrm{~kg}$ $(\mathrm{p}=0.045)$.

\section{Discussion}

To our knowledge, this is the first study of body composition and hand grip strength in octogenarian 
community-dwelling Swedes. In this highly selected group with regards to socioeconomic status, health and functional independence, our findings indicate wellpreserved body energy and protein stores, as reflected in fat free mass and fat mass index. Hand grip strength decreased over four years of follow-up in men, but not in women.

Since measurements were carried out as home visits, standard laboratory conditions were not possible to obtain, though the same two investigators carried out all visits, minimizing inter-observational variation. We chose to use hand grip strength as a measure of muscle strength since data on this was available from the previous study (10).

The present population is in better health condition than Swedish 80-90-year olds in general (10). Subject characteristics and health status support the findings of well-preserved body energy and protein stores, and muscle strength. Both sexes have a lower phase angle compared to the 75-year olds from the H70-study in

Table 2

Anthropometry, body composition and hand grip strength by gender

\begin{tabular}{|c|c|c|c|c|}
\hline & $\begin{array}{l}\text { Men n=51 } \\
(\text { Mean } \pm \text { SD) }\end{array}$ & Range & $\begin{array}{l}\text { Women } n=51 \\
(\text { Mean } \pm \text { SD) }\end{array}$ & Range \\
\hline \multicolumn{5}{|l|}{ Anthropometry } \\
\hline Height $(\mathrm{cm}) *$ & $175( \pm 6.7)$ & $157-191$ & $159( \pm 4.3)$ & $151-170$ \\
\hline Weight $(\mathrm{kg}) *$ & $75.6( \pm 7.8)$ & $60.8-93.5$ & $63.1( \pm 9.0)$ & $42.6-90.0$ \\
\hline BMI $\left(\mathrm{kg} / \mathrm{m}^{2}\right)$ & $24.7( \pm 2.3)$ & $19.5-33.4$ & $24.8( \pm 3.6)$ & $16.8-34.2$ \\
\hline Underweight (\%)a & 14 & & 16 & \\
\hline Normal weight (\%) & 84 & & 70 & \\
\hline Obese (\%)b & 2 & & 14 & \\
\hline Normal muscle (\%) & - & & 12 & \\
\hline Moderate sarcopenia (\%) & 20 & & 45 & \\
\hline Severe sarcopenia (\%)c & 80 & & 43 & \\
\hline \multicolumn{5}{|l|}{ Body Composition } \\
\hline $\operatorname{TBW}(1) *$ & $40.3( \pm 4.5)$ & $31.0-50.3$ & $30.5( \pm 3.5)$ & $22.8-41.8$ \\
\hline $\operatorname{ECW}(1) *$ & $19.4( \pm 2.0)$ & $14.9-24.2$ & $13.6( \pm 1.5)$ & $9.7-18.4$ \\
\hline $\operatorname{ICW}(1) *$ & $20.9( \pm 2.7)$ & $16.1-27.6$ & $16.9( \pm 2.2)$ & $12.0-23.4$ \\
\hline $\mathrm{FM}(\mathrm{kg})$ & $20.5( \pm 4.9)$ & $8.2-31.3$ & $21.4( \pm 5.8)$ & $8.5-34.8$ \\
\hline FM (\%) & $27( \pm 5.4)$ & $11-36$ & $33( \pm 5.6)^{*}$ & $15-45$ \\
\hline $\mathrm{FFM}(\mathrm{kg}) *$ & $55.1( \pm 6.1)$ & $42.3-68.7$ & $41.7( \pm 4.7)$ & $31.2-57.1$ \\
\hline FMI $\left(\mathrm{kg} / \mathrm{m}^{2}\right) *$ & $6.7( \pm 1.6)$ & $2.6-9.4$ & $8.4( \pm 2.3)$ & $3.3-14.6$ \\
\hline FFMI $\left(\mathrm{kg} / \mathrm{m}^{2}\right) *$ & $18.0( \pm 1.8)$ & $14.7-24.5$ & $16.4( \pm 1.9)$ & $12.3-21.8$ \\
\hline $\operatorname{SMM}(\mathrm{kg})^{\star} \mathrm{d}$ & $24.7( \pm 2.7)$ & $18.5-30.5$ & $15.0( \pm 2.5)$ & $9.0-20.8$ \\
\hline $\operatorname{SMM}(\%)^{*}$ & $32.8( \pm 2.8)$ & $27.7-40.6$ & $23.8( \pm 3.3)$ & $15.8-33.3$ \\
\hline SMI $\left(\mathrm{kg} / \mathrm{m}^{2}\right)$ & $8.0( \pm 0.5)$ & $6.8-9.2$ & $5.9( \pm 0.9)$ & $3.5-7.9$ \\
\hline Phase Angle $\left({ }^{\circ}\right) \mathrm{e}$ & $4.4( \pm 0.6)$ & $3.4-5.9$ & $4.2( \pm 0.6)$ & $3.0-6.5$ \\
\hline Phase Angle SDSf & $-1.01( \pm 0.69)$ & $-2.43 \neg-0.86$ & $-1.14( \pm 0.72)$ & $-2.48-1.68$ \\
\hline \multicolumn{5}{|l|}{ Strength } \\
\hline HGS2008 $(\mathrm{kg})^{*} \mathrm{~g}$ & $37.2( \pm 7.8)$ & $11.0-52.0$ & $20.2( \pm 4.4)$ & $12.0-32.0$ \\
\hline HGS2012 $(\mathrm{kg})^{\star} \mathrm{h}$ & $34.1( \pm 7.5)$ & $20.0-50.0$ & $19.5( \pm 4.0)$ & $10.0-29.0$ \\
\hline Low muscle strength2008c (\%) & 16 & & 45 & \\
\hline Low muscle strength2012c, h (\%) & 22 & & 60 & \\
\hline
\end{tabular}

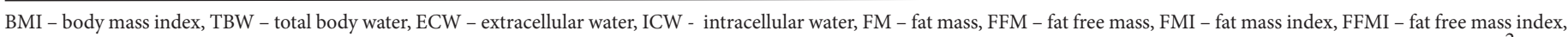

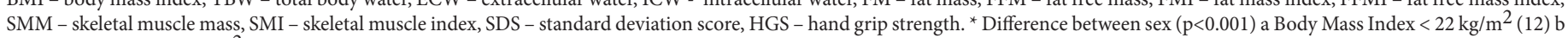

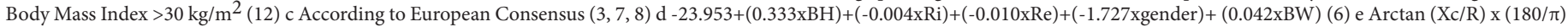
(17) $\mathrm{f}(\mathrm{x}-\mathrm{MPhA}) / \mathrm{SD}$ (17) g Hand grip strength; baseline data from previous study (10) h Hand grip strength from 2012 is missing data from two participants 
accordance to normal age changes $(6,17)$.

High BMI in old age has been associated with lower risk of morbidity and mortality $(8,19)$. Only $14 \%$ of men and $16 \%$ of women were considered underweight according to cut-offs, indicating good nutritional status compared to previous studies $(6,8)$. Based on the high measured levels of hand grip strength in present population, low BMI could be interpreted as a sign of physical fitness rather than risk of malnutrition (20). Unfortunately data on body weight during life course is missing.

Our findings include a very high prevalence of low muscle mass but not of low handgrip strength (3). This could indicate a possible altered relation of muscle mass and function in healthy octogenarians. However, in the absence of lower limb muscle function, this remains speculative.

In the present population aged 83 - 96 years we found a weak relation between age, fat free mass and physical function measured by hand grip strength. As the participants were healthy for their age, evidenced by living in ordinary homes, independent of municipal home care service and without cognitive impairment, our results may give an indication of what constitutes a healthy body composition in oldest old.

There are few studies on body composition in older adults. Body composition appears to be more associated with declining physical function than gender or chronological age. Applied gender specific cut-offs for sarcopenia in this population implies moderate or severe sarcopenia in $100 \%$ of men and $88 \%$ of women. Our group of 80-90-year olds shows a weak association between chronological and biological age. Results could serve as a starting point for reference values on healthy body composition in oldest old.

\section{Conclusion}

This healthy and functionally independent group of older adults was found to show well-preserved body energy, protein stores, and muscle strength. Longitudinal changes of hand grip strength were more apparent in men than in women. Body composition appears to be more associated with declining physical function than gender or chronological age. These results could serve as a starting point for establishing reference values for healthy body composition in oldest old.

Acknowledgement: Great acknowledgements and thanks to Elderly in the Risk Zone and all participants, Susanne Gustafsson and Vibeke Malmros.

Statement of authorship: S. Dahlin-Ivanoff supplied the study population. Collection of data was performed by A. Lindblad who also wrote the manuscript with support from E. Rothenberg and guidance from I. Bosaeus and S. DahlinIvanoff.

\section{Conflict of interest: Authors have no conflict of interest.}

Funding: This article was financially supported by the Swedish state under the ALF agreement. Supporting organizations to Elderly Persons in the Risk Zonestudy; the Swedish Institute for Health Sciences, the Research and Development
Council of the County of Södra Älvsborg, the Swedbank Sjuhärads Foundation for Research at the Hospital of Södra Älvsborg, and the Focus Foundation in Borås. Ms. Lindblad has nothing to disclose. Dr. Dahlin-Ivanoff has nothing to disclose. Dr. Bosaeus has nothing to disclose. Dr. Rothenberg has nothing to disclose.

\section{References}

1. Boirie Y, Gachon P, Beaufrere B. Splanchnic and whole-body leucine kinetics in young and elderly men. The American journal of clinical nutrition. 1997 Feb;65(2):489-95. PubMed PMID: 9022534. Epub 1997/02/01. eng.

2. Buffa R, Floris GU, Putzu PF, Marini E. Body composition variations in ageing. Collegium antropologicum. 2011 Mar;35(1):259-65. PubMed PMID: 21667542. Epub 2011/06/15. eng.

3. Cruz-Jentoft AJ, Baeyens JP, Bauer JM, Boirie Y, Cederholm T, Landi F, et al Sarcopenia: European consensus on definition and diagnosis: Report of the European Working Group on Sarcopenia in Older People. Age and ageing. 2010 Jul;39(4):412-23. PubMed PMID: 20392703. Pubmed Central PMCID 2886201. Epub 2010/04/16. eng.

4. Short KR, Nair KS. Mechanisms of sarcopenia of aging. Journal of endocrinological investigation. 1999;22(5 Suppl):95-105. PubMed PMID: 10442578. Epub 1999/08/12. eng.

5. Dey DK, Bosaeus I, Lissner L, Steen B. Body composition estimated by bioelectrical impedance in the Swedish elderly. Development of populationbased prediction equation and reference values of fat-free mass and body fat for 70- and 75-y olds. European journal of clinical nutrition. 2003 Aug;57(8):909-16. PubMed PMID: 12879085. Epub 2003/07/25. eng.

6. Tengvall M, Ellegard L, Malmros V, Bosaeus N, Lissner L, Bosaeus I. Body composition in the elderly: reference values and bioelectrical impedance spectroscopy to predict total body skeletal muscle mass. Clinical nutrition (Edinburgh, Scotland). 2009 Feb;28(1):52-8. PubMed PMID: 19010572. Epub 2008/11/18. eng.

7. Janssen I, Heymsfield SB, Ross R. Low relative skeletal muscle mass (sarcopenia) in older persons is associated with functional impairment and physical disability. Journal of the American Geriatrics Society. 2002 May;50(5):889-96. PubMed PMID: 12028177. Epub 2002/05/25. eng.

8. Janssen I, Baumgartner RN, Ross R, Rosenberg IH, Roubenoff R. Skeleta muscle cutpoints associated with elevated physical disability risk in older men and women. American journal of epidemiology. 2004 Feb 15;159(4):41321. PubMed PMID: 14769646. Epub 2004/02/11. eng.

9. Schaap LA, Koster A, Visser M. Adiposity, Muscle Mass, and Muscle Strength in Relation to Functional Decline in Older Persons. Epidemiologic reviews. 2012 Dec 4. PubMed PMID: 23221972. Epub 2012/12/12. Eng.

10. Gustafsson S, Wilhelmson K, Eklund K, Gosman-Hedstrom G, Ziden L, Kronlof GH, et al. Health-promoting interventions for persons aged 80 and older are successful in the short term--results from the randomized and three-armed Elderly Persons in the Risk Zone study. Journal of the American Geriatrics Society. 2012 Mar;60(3):447-54. PubMed PMID: 22409735. Epub 2012/03/14. eng.

11. Rinder L, Roupe S, Steen B, Svanborg A. Seventy-year-old people in Gothenburg. A population study in an industrialized Swedish city. Acta medica Scandinavica. 1975 Nov;198(5):397-407. PubMed PMID: 1081814. Epub 1975/11/01. eng.

12. Steen B, Djurfeldt $H$. The gerontological and geriatric population studies in Gothenburg, Sweden. Zeitschrift fur Gerontologie. 1993 May-Jun;26(3):163-9. PubMed PMID: 8337910. Epub 1993/05/01. eng.

13. Organisation WH. Obesity and Overweight 2013 [updated March 20132013 06-02]. Available from: http:/ / www.who.int/mediacentre/factsheets / fs311/ en/.

14. Welfare SNBoHa. Nutrition for good health care [Näring för god vård och omsorg] (In Swedish). 2011.

15. Instrument L. JAMAR Hydrolic Hand Dynamometer User Instructions. 2004. 16. Impedimed. SFB7 User Instructions.

17. Bosy-Westphal A, Danielzik S, Dorhofer RP, Later W, Wiese S, Muller MJ Phase angle from bioelectrical impedance analysis: population reference values by age, sex, and body mass index. JPEN Journal of parenteral and enteral nutrition. 2006 Jul-Aug;30(4):309-16. PubMed PMID: 16804128. Epub 2006/06/29. eng

18. Kyle UG, Schutz Y, Dupertuis YM, Pichard C. Body composition interpretation. Contributions of the fat-free mass index and the body fat mass index. Nutrition (Burbank, Los Angeles County, Calif). 2003 JulAug;19(7-8):597-604. PubMed PMID: 12831945. Epub 2003/07/02. eng.

19. Flicker L, McCaul KA, Hankey GJ, Jamrozik K, Brown WJ, Byles JE, et al. Body mass index and survival in men and women aged 70 to 75 . Journal of the American Geriatrics Society. 2010 Feb;58(2):234-41. PubMed PMID 20370857. Epub 2010/04/08. eng.

20. Gunther CM, Burger A, Rickert M, Crispin A, Schulz CU. Grip strength in healthy caucasian adults: reference values. The Journal of hand surgery. 2008 Apr;33(4):558-65. PubMed PMID: 18406961. Epub 2008/04/15. eng. 